\title{
Seasonal changes and the influence of tree species and ambient temperature on the fission-fusion dynamics of tree-roosting bats
}

\author{
Ireneusz Ruczyński ${ }^{1}$ (1) Kamil A. Bartoń ${ }^{2}$
}

Received: 15 April 2019 / Revised: 10 April 2020 / Accepted: 20 April 2020 / Published online: 4 May 2020

(C) The Author(s) 2020

\begin{abstract}
Many species of bats live in dynamic associations in which individuals aggregate or split into smaller or larger groups, moving between roost sites, but factors influencing group size and roost switching decisions in bats living in fission-fusion societies are poorly understood. To test the extent to which fission-fusion dynamics are species-specific and shaped by environmental factors, we radiotracked two closely related species: noctule bats Nyctalus noctula and Leisler's bats $N$. leisleri in well-preserved, old-growth stands of the Białowieża Forest, where roost availability and diversity is high and bats can potentially freely exhibit fission-fusion behaviour. We estimated the number of bats per roost and noted the tree species selected as roost sites. We evaluated the influence of ambient temperature and roost tree species on bat group size and the process of roost switching, and their seasonal component. Our results revealed that bat group size showed species-specific differences in seasonal variation, relationship to ambient temperature and tree species. The number of noctule bats emerging from a roost was relatively stable with a weak tendency to decrease during the breeding season while the number of Leisler's bats emerging from a roost increased when the juveniles started to be volant. Group size of noctule bats increased with ambient temperature. Leisler's bats formed smaller colonies in oaks and ashes than in other tree species. Roost switching rate was associated with ambient temperature and tree species selected by the bats. The bats changed roosts more frequently when the minimum ambient temperature increased, and less often in ashes than in oaks and other tree species. Our results show that bat group size and roost switching behaviour are shaped by both environmental factors and the stage of reproduction.
\end{abstract}

\section{Significance statement}

Environmental factors may affect group size and roost switching behaviour of bats forming fission-fusion associations, but this is expected to vary depending on body size, environmental conditions, as well as seasonally. Few studies have explored this behaviour in tree-dwelling bats and examined how it differs between species. Here, we studied the group size dynamics and the process of roost switching in closely related bat species living in well-preserved, European old-growth forests, for which the knowledge of these patterns is particularly poor. We demonstrate for the first time that bat group size and roost switching rate relates to roost tree species selected by bats, the ambient temperature and varies seasonally, and that these effects are speciesspecific. The results point out the importance of the availability of suitable roost trees providing a range of microclimatic conditions for maintaining efficient fission-fusion dynamics throughout the reproductive period.

Keywords Roosts $\cdot$ Reproduction $\cdot$ Pregnancy $\cdot$ Lactation $\cdot$ Post-lactation $\cdot$ Social warming

Communicated by M. Knoernschild

Electronic supplementary material The online version of this article (https://doi.org/10.1007/s00265-020-02840-1) contains supplementary material, which is available to authorized users.

Ireneusz Ruczyński

iruczyns@ibs.bialowieza.pl

1 Mammal Research Institute, Polish Academy of Sciencess, Stoczek 1, 17-230 Białowieża, Poland

2 Institute of Nature Conservation, Polish Academy of Sciences, al. A. Mickiewicza 33, 31-120 Kraków, Poland

\section{Introduction}

Many mammals, such as primates, elephants, cetaceans, bats, carnivores or rodents live in social groups (Dunbar and Shultz 2007; Silk 2007). The groups may vary from highly cohesive with stable membership to highly fluid (Aureli et al. 2008). An example of the latter are temperate forest-dwelling bats, forming dynamic associations called fission-fusion societies (Kerth and König 1999; Kerth 2008, 2010; Popa-Lisseanu et al. 2008), in which individuals fuse or split into groups of 
different sizes maintaining relatively stable social bonds. The factors shaping changes of group size in fission-fusion associations have been debated (Kerth and König 1999; Kerth 2010), but it is generally accepted that the group size is a result of a trade-off between the benefits and costs of association (Silk 2007).

Social warming has been suggested as a key factor in determining group size in bats (Willis and Brigham 2007), with the group size explaining the thermoregulatory patterns better than environmental factors (Willis and Brigham 2007; Russo et al. 2017). However, bats may also control energetic expenditure by selecting different roost types, e.g. boxes or trees and different tree species (Kerth et al. 2001; Ruczyński 2006; Ruczyński and Bogdanowicz 2008), or by an active use of torpor, which could also be a response to environmental conditions and food availability (Rambaldini and Brigham 2008; Czenze et al. 2017).

Group size also affects the efficiency of searching for food and roosts (Ruczyński et al. 2007; Dechmann et al. 2010; Ruczyński and Bartoń 2012), which in turn may promote the stabilization of the group size (Sueur et al. 2011). Larger groups, however, may suffer from increased risk of infestation, disease transmission and food competition (Reckardt and Kerth 2007; Postawa and Szubert-Kruszyńska 2014). Therefore, bat group size in fission-fusion dynamics is a result of a trade-off between factors promoting smaller or larger groups, which change in time and space. These factors are still poorly understood in forest-dwelling bats. In fission-fusion dynamics, roost switching is a mechanism allowing for changing group size and the selection of new roosts offering a more favourable microclimate, placement, lower infestation level, etc. Patriquin et al. (2016) showed that roost switching occurred in response to changes in ambient conditions, suggesting that bats sought more suitable roosting conditions. Ecophysiological differences among bat species determine their preferences for roosting sites characterised by different microclimatic conditions (Bartonička and Řehák 2007; Boyles 2007; Webber and Willis 2018). It may generate a species-specific reaction to environmental conditions and fission-fusion dynamics. However, so far little is known as to which factors play a role in shaping group size and roost switching dynamics, what kind of impact they have and whether this process is species-specific.

We hypothesise that the number of bats gathering in a tree cavity differs between these species, depending on the bat energetic demands and environmental conditions. Conditions contributing to the temperature inside the roosting places include the ambient temperature, $T_{a}$, and the species of the tree. Higher number of bats in a roost should be observed when $T_{a}$ is low and when the animals need to maintain high body temperature during intensive juvenile growth and milk production, i.e. gestation and lactation. Forearm length (FA) of pups at their first flight usually is at $95 \%$ of adult FA length and the growth is almost finished; however, pups' body mass is clearly smaller than adult body mass (Barclay 1994; Kunz and Robson 1995; Hoying and Kunz 1998). Keeping a high body temperature seems to be less important for adults and juveniles when juveniles become volant because they need to invest more energy in storing fat reserves, so low body temperature as well as smaller groups should be preferred (Willis and Brigham 2007). This process should be even more intensive during the post-lactation period when females no longer need to maintain high body temperatures necessary for producing milk, juveniles are hunting independently and juvenile growth is almost finished (Pretzlaff et al. 2010; Nad'o et al. 2017). We therefore expect the frequency of roost switching to be higher during the stage when juveniles are more mobile, and particularly during warm weather, when the benefits from social warming are smaller.

For this study, we have chosen two closely related noctule species: the noctule bat Nyctalus noctula and Leisler's bat $N$. leisleri. The noctule bat is larger than Leisler's bat (respectively 15-40 and 11-20 g, Dietz et al. 2009). In smaller animals, maintaining a high body temperature and metabolic rate can be energetically more demanding (Porter and Kearney 2009); therefore, Leisler's bats are expected to form larger groups.

The aim of this study was to (1) estimate the number of bats in tree cavities and how it changes during the breeding season in two closely related bat species; (2) evaluate the influence of ambient temperature and roost type (tree species) on bats' group size; and (3) evaluate the seasonal changes, the effect of ambient temperature, and roost type on the process of roost switching.

\section{Methods}

\section{Study area}

The study was conducted in the Białowieża Forest, eastern Poland. The study area $\left(100 \mathrm{~km}^{2}\right)$ covered well-preserved stands of the Białowieża National Park (BNP), as well as parts of the managed forest with old-growth remnants (over 100 years old). This is a mosaic forest dominated by deciduous, mixed deciduous, black alder bog, streamside alder-ash, mixed coniferous and coniferous stands (Faliński 1986). The study site is described in more detail in Ruczyński et al. (2017).

\section{Capture and radio tracking}

We captured bats with mist nets by small forest rivers (Łutownia, Narewka, Hwoźna and Złota) and a small pond at the edge of the forest (BNP), from 1998 to 2002. We identified the species, sex, age and reproductive status of the bats. 
The details are described in Ruczyński and Bogdanowicz (2008) and Ruczyński et al. (2017).

We localised the roosts with the use of radiotelemetry. The captured bats were fitted with radio-transmitters $(0.5-0.7 \mathrm{~g})$ and were tracked to roosts the next day (for details on tracking, see Ruczyński and Bogdanowicz 2005, 2008; Ruczyński et al. 2017). It was not possible to record data blind because our study involved focal animals in the field. The mass of a transmitter never exceeded $5 \%$ of the bat's body mass (Aldridge and Brigham 1988). The numbers of bats in tree cavities were estimated on the basis of visual observations carried out during the evening emergence of bats. The recorded bat group sizes are associated with the tracked individuals. Usually, only one tracked bat was present in a single roost. Most of the tree cavities were situated high above ground; therefore, the numbers of bats may have been underestimated. The recorded group size did not include young while they stayed in the tree cavities. Offspring were first counted when they became volant, 4-5 weeks after parturition.

\section{Statistical analyses}

We estimated the effects of roost tree species and ambient temperature on bat group size and the probability of roost switching and their seasonal component. For the ambient temperature, $T_{a}$, we used minimum daily temperatures (Pretzlaff et al. 2010) measured at the meteorological station in Białowieża on the night preceding the observation day. Tree species other than oak and ash (i.e. alder, lime, hornbeam, maple and pine) were pooled together as 'other', since each of these species constituted individually less than $7.4 \%$ of all records (oak $65 \%$, ash $21 \%$, other species $14 \%$ of all records). In the cases when two bats were present in one roost on the same day $(N=10)$, we excluded the record of the individual that was tracked for a shorter period.

For the modelling of roost switching and group size, we used generalized linear mixed models, including the random effect of individual and assuming by-individual, first-order autoregressive correlation structure to account for the longitudinal setting of the data (the details of model fitting are described in the Supplementary Material). The full model included the effects of $T_{a}$ and its change (the difference between the current and the preceding day, $\mathrm{d} T_{a}$ ), tree species, a nonlinear effect of the day of the year (as quadratic polynomial), as well as the interactions of these variables with a categorical variable representing the bat species. We performed model simplification by iteratively removing the least significant terms (up to a moderate $p$ level of 0.1 ) from the full model (Hastie et al. 2009).

In the model of bat group size, we used a negative binomial error distribution with a logarithmic link to account for overdispersion in the count data. To model roost change probability, we used a binary response variable indicating whether the group would switch roosts on the following day. In the latter analysis, we fitted models with binomial error distribution and a logit link function (chosen based on comparisons of model fit performance with alternative functions) to the subset of the data where individuals were tracked for at least two consecutive days $(N=285)$. Where tree species was included in the final model, we conducted post hoc tests with Tukey's HSD to compare differences among these groups, on per-species models to account for the species differences. All analyses were performed using $\mathrm{R}$ software, version 3.6.0 ( $\mathrm{R}$ Core Team 2019), and packages 'mgcv' for model fitting (Wood 2017), 'effects' for effect plots (Fox 2003), and 'multcomp' for post hoc tests (Hothorn et al. 2008).

\section{Results}

We obtained data from 48 bats (24 noctule bats and 24 Leisler's bats), each of which visited from 1 to 5 cavities (mean $2.5 \pm 1.05 \mathrm{SD}$ ). In total, 300 records were used, of which, 107 contained information on bat group size, and 285 on roost switching.

\section{Bat group size}

The bats were solitary or formed groups of up to 97 individuals (mean 17.53 $\pm 16.1 \mathrm{SD}$ ). Groups of noctule bats were smaller and less variable ( $15.75 \pm 7.9$, up to 34 individuals) than those of Leisler's bats (mean $25.0 \pm 19.1$ ) (Fig. 1). Group size of Leisler's bats peaked when pups started to be volant, followed by a decrease at the end of the season. Noctule bats showed a slowly decreasing trend over the course of the year (although statistically not significant, Fig. 1). The final model for the group size included effects of bat species interacting with minimum ambient temperature, tree species and seasonal change (Table 1), and explained $17.1 \%$ of deviance. The model showed the differences between both species in the selection of tree species and to a lesser extent in the seasonal component. Specifically, the model confirmed a nonlinear seasonal change in Leisler's bats $(t=-2.28, p=0.03)$, and no trend in noctule bats $(t=-0.38, p=0.71)$ (Fig. 2, Table S1 in the Supplementary Material). In Leisler's bats, the groups were significantly smaller in ash $(z=2.75, p=0.02)$ and oak $(z=$ 2.31, $p=0.05$ ) cavities compared to other tree species (Fig. 2, Table S2). There was no clear effect of tree species in noctule bats (Fig. 2, Table S2). The model also indicated a positive relationship of group size with the minimum ambient temperature in noctule bats (Fig. 2, Table S1).

\section{Roost switching rate}

The bats were observed in one roost for 1 to 12 days (mean $2.6 \pm 2.0 \mathrm{SD}$ days). Noctule bats stayed in a roost on average 
Fig. 1 Group size in the two studied bat species during the reproductive season. Dashed line and the shaded area show the seasonal trend (mean $\pm 95 \%$ confidence interval). Vertical, dashed lines denote the date of first observation of lactating females (LF) and volant pups (VP)

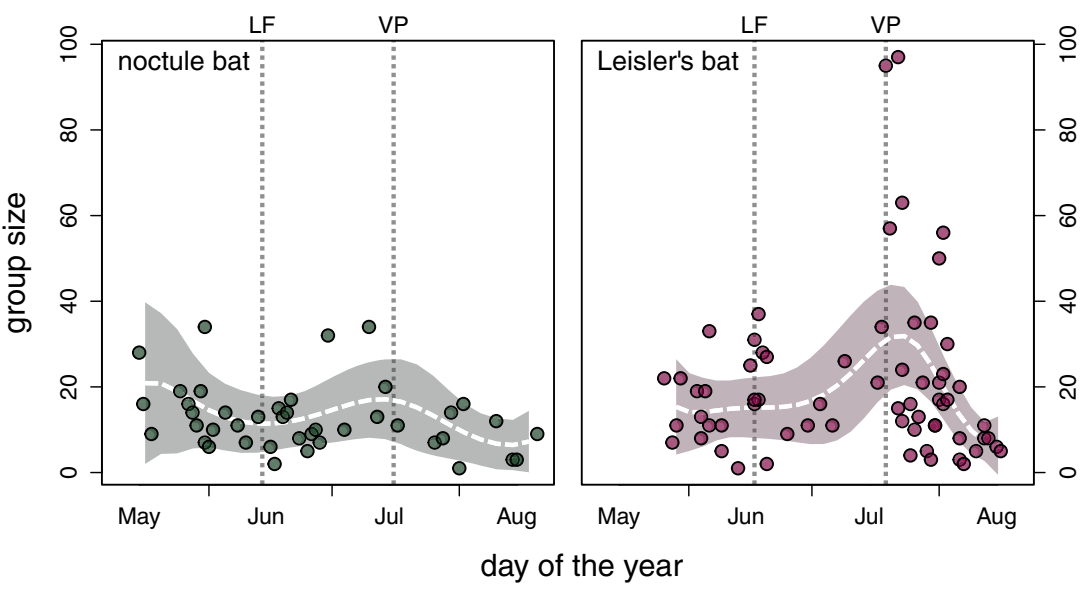

for $2.76 \pm 2.4$ and Leisler's bats for $2.50 \pm 1.7$ days. The daily roost switching rate was $0.23(N=137)$ and $0.31(N=148)$, respectively for noctule and Leisler's bats.

The final model included the effects of the ambient temperature change, as well as species-wise effects of roost tree species and seasonal component (Table 1), explaining $8.5 \%$ of deviance. The model showed that early in the year, the switching rate in noctule bats is lower than in Leisler's bats, and it starts to increase at the beginning of July, when pups are still flightless (Fig. 3). There was a significant difference to Leisler's bats (Table 1), where the switching rate did not show

Table 1 Anova (type II) table of the final models for bat group size and roost switching. The columns give the model term's degree of freedom, the $F$ test statistic and associated $p$ value. 'Species' is a categorical variable representing the two bat species. ' $T_{a}$ ' is the minimum ambient temperature and ' $\mathrm{d} T_{a}$ ' is its day-to-day change. 'Tree species' is a categorical variable with three levels. 'Day of the year' is represented as a second-order polynomial

\begin{tabular}{llll}
\hline Model term & df & $F$ & $p$ \\
\hline Group size & & & \\
Species & 1 & 2.01 & 0.16 \\
$T_{a}$ & 1 & 4.21 & 0.04 \\
Day of the year & 2 & 1.05 & 0.35 \\
Tree species & 2 & 1.27 & 0.29 \\
Species * $T_{a}$ & 1 & 2.36 & 0.13 \\
Species * Tree species & 2 & 3.37 & 0.04 \\
Day of the year * Species & 2 & 2.47 & 0.09 \\
Roost switching & & & \\
Species & 1 & 0.52 & 0.47 \\
d $T_{a}$ & 1 & 6.46 & 0.01 \\
Day of the year & 2 & 2.79 & 0.06 \\
Tree species & 2 & 2.68 & 0.07 \\
Day of the year * Species & 2 & 2.13 & 0.12 \\
Species * Tree species & 2 & 4.00 & 0.02 \\
\hline
\end{tabular}

Significant effects (within 95\% CI) are denoted in italics fluctuations over the whole reproductive period (Fig. 3, Table S1).

The overall effect of roost tree species was not significant (Table 1). Also, the post hoc comparisons showed little differences between tree species (Table S2). In noctule bats, the switching rate was highest in the ash trees, and lowest in the tree species from the 'other' group. Conversely, in Leisler's bats, the switching rate was highest when they roosted in the 'other' tree species. In both bat species, roost switching rate rose with increasing change in ambient temperature (Fig. 3).

\section{Discussion}

Our results show that the size of bat groups and the rate at which they switch between roosting sites is affected by different factors in a species-specific manner. We found that largest groups of Leisler's bats emerged from roosts when the juveniles started to be volant, while noctule bats increased the frequency of roost switching during the reproductive period. In contrast to our hypothesis, the minimum ambient temperature, $T_{a}$ had no negative influence on group size (conversely, our results suggest a positive effect in noctule bats). $T_{a}$ also had no effect on the roost switching rate; however, the effect of the day-to-day change in $T_{a}$ was positive. Our results confirm that bat group size and roost switching behaviour are related to the stage of reproduction and environmental factors.

In line with our first hypothesis, we observed speciesspecific differences in the number of bats emerging from roosts, with groups of Leisler's bats tending to be larger than those of noctule bats. Keeping high body temperature during cold weather is energetically expensive for small mammals; therefore, to minimize energetic costs, bats should stay in the thermoneutral zone when they remain normothermic (Pretzlaff et al. 2010). Social warming seems to be the most effective method of elevating temperature and creating optimal thermal conditions in roosts, especially when $T_{a}$ is low (Scantlebury et al. 2006; Willis and Brigham 2007; Pretzlaff 


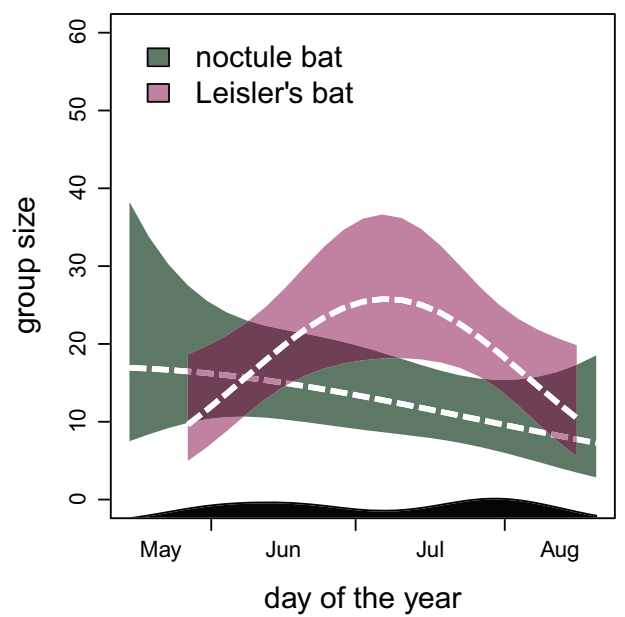

Fig. 2 Results of the final model for bat group size. The panels show predictions of the seasonal changes, in different roost tree species, and along the ambient temperature gradient, for the two studied bat species. The remaining explanatory variables were kept at their mean values or

et al. 2010). Leisler's bats, smaller than noctule bats, potentially need larger groups for maintaining suitable microclimatic conditions in roosts, which may explain the difference in the group size dynamics when the juveniles start to be volant. The number of emerging Leisler's bats in some roosts increased until the end of July. These large groups suggest that juveniles stay with mothers in the same roosts or fuse with other individuals. The lack of such an increase in noctule bats indicates that in this species colonies split into smaller groups upon the emergence of young, even if the young stay with their mothers (Ripperger et al. 2019).

During most of the lactation period, juveniles grow intensively (Kunz and Robson 1995; Hoying and Kunz 1998; Speakman 2008), and the prolonged torpor of adults and juveniles may slow down offspring development (Racey 1973; Racey and Swift 1981; but see Willis et al. 2006). Therefore, maintaining large groups during lactation is an energy-saving

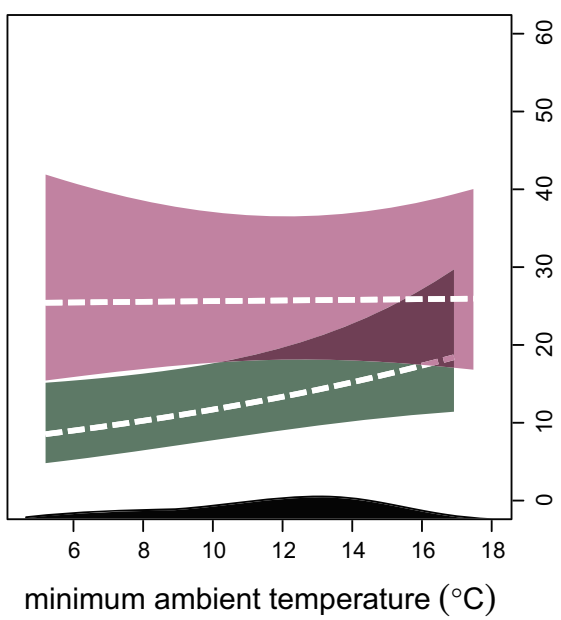

most common factor levels. Bullets and white line show the mean, with whiskers or shading denoting $95 \%$ confidence intervals. The distribution of the original data is shown at the bottom axis as a kernel density plot or a histogram for categorical data

strategy that avoids the use of torpor, due to the additive effect of juveniles and adults on the roost microclimate. However, large groups can suffer from increased risk of parasite infestation (Kaňuch et al. 2005).

When they start to be volant, juveniles have almost finished intensive growth and begin to hunt independently (Kunz and Robson 1995; Hoying and Kunz 1998), accumulating fat reserves for their first winter (Kunz et al. 1998). More frequent use of torpor can foster fat accumulation by decreasing the costs of body heating (Dietz and Kalko 2006; Pretzlaff et al. 2010; McGuire et al. 2014). The large colonies of Leisler's bats observed after emergence of young suggest that females still lactated at that time, and juveniles benefit from social warming (Willis and Brigham 2007). Information transfer and mother's guidance may also play a role in forming large colonies during that stage (Willis and Brigham 2007; Ripperger et al. 2019). This explanation is also supported by
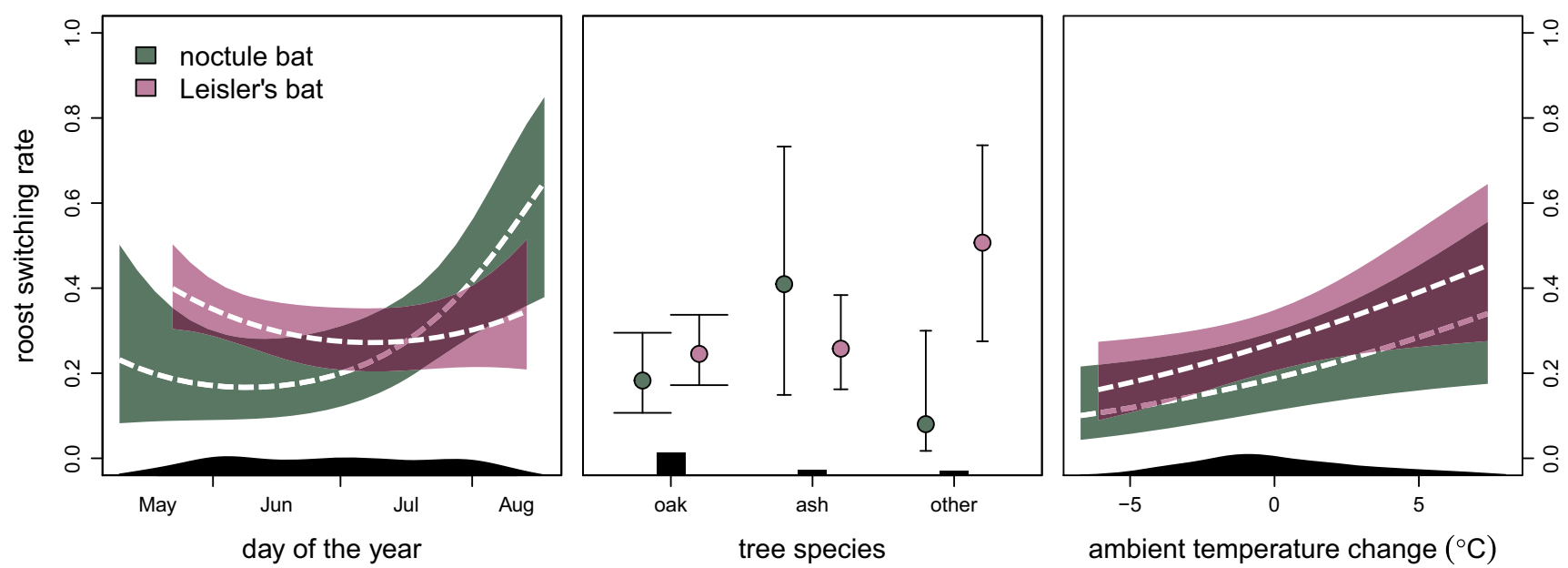

Fig. 3 Results of the final model for roost switching rate. The panels show predictions of the seasonal changes, in different roost tree species, and along the range of change in the ambient temperature. See the description for Fig. 2 for details 
the observations of Leisler's and Bechstein's bats in which group size was relatively large during pregnancy and lactation, and decreased mostly during the post-lactation period (Pretzlaff et al. 2010; Nad'o et al. 2017).

Contrary to our expectations, we found a positive relation between $T_{a}$ and noctule bats' numbers in roosts, and no relation between group size and $T_{a}$ in Leisler's bats. A positive or no relation between $T_{a}$ and the number of bats in roosts in our studies is presumably a result of high flexibility in torpor use by bats and thermal conditions inside roosts, which we did not monitor in this study. Under laboratory conditions, Webber and Willis (2018) observed that bats tend to form larger groups when roost temperature, $T_{r}$ was low relative to $T_{a}$, and the difference between $T_{r}$ and $T_{a}$ was at its lowest (Webber and Willis 2018). Studies conducted in the field showed that Bechstein's bats remained mostly normothermic and group sizes were relatively large during pregnancy and lactation, presumably to benefit from social thermoregulation (Pretzlaff et al. 2010). In contrast, smaller groups were formed on days when bats used torpor, which occurred mostly during the post-lactation period (Pretzlaff et al. 2010). The positive relation between $T_{a}$ and the numbers of noctule bats may also suggest that some noctule bats did not hunt during the night (thus, they were not counted) at low $T_{a}$.

The roosts vary in their thermal inertia, due to the height above ground, entrance size, wall thickness and canopy cover (Ruczyński and Bogdanowicz 2005; Ruczyński 2006). Therefore, $T_{r}$ may differ from $T_{a}$ in a wide range, and in this study, the tree species served as a crude proxy for roost microclimate conditions (Ruczyński and Bogdanowicz 2008). Noctule and Leisler's bats tend to prefer oaks when $T_{a}$ is low, while they prefer ashes in high temperatures (Ruczyński and Bogdanowicz 2008) indicating that microclimate conditions, and indirectly the tree species, are actively selected by bats. Smaller groups of Leisler's bats in oak and ash (the most selected roost tree species) than in other trees may be linked to the stage of the reproductive period: the 'other' trees (mostly alder) were largely selected when group size increased after the pups start to be volant, while oaks and ashes are used over the whole reproductive period. Our observations are in line with the hypothesis that the number of bats in the roosts is not a simple response to the ambient conditions but also a result of roost quality. To our knowledge, this is the first field study demonstrating that the selection of tree species by bats is linked with the group size.

The rate of roost switching was similar in both bat species despite the differences in body size. The results did not confirm that the switching behaviour is connected to the ambient temperature as such; however, we found that both species were more likely to leave a roost as the temperature increased. A larger increase, or smaller decrease, of ambient temperature from 1 day to the next has a positive effect on the roost switching rate. The roost tree also may have an effect - the studied Leisler's bats stayed longer in oaks and ashes than in other tree species, although the difference was not significant. Therefore, the roost switching rate may be explained by the necessity of selecting more suitable roosting conditions after changes in weather conditions but may also be shaped by roost parameters. The results of Patriquin et al. (2016) on northern longeared bats, where roost switching rates increased at higher temperatures and depended on tree condition, further support that roost switching behaviour is a species-specific trait and is shaped by roost parameters.

Accounting for social mechanisms of maintaining group cohesion, which may play an important role in shaping group size and the process of roost switching (Chaverri et al. 2013; Nad'o and Kaňuch 2015; Nad'o et al. 2017), should greatly improve the models explaining the roosting behaviour of bats. Ecological similarities among bat species were observed in previous studies analysing roost site selection and activity patterns (Ruczyński and Ruczyńska 2000; Ruczyński and Bogdanowicz 2005, 2008; Ruczyński et al. 2017). That suggests the mechanisms of fission-fusion dynamics in closely related species of bats living in the same area are similar, but not exactly the same.

Our study demonstrated that tree species and temperature influence the fission-fusion dynamics of European forest-dwelling bats in terms of group size and roost switching rate, depending on the stage of the reproductive period. A lack of clear effects of $T_{a}$ on group size points out the complexity of bats' behaviour, therefore monitoring of components such as social bonds, food availability, body temperature, $T_{a}$ and $T_{r}$, and possibly the metabolic rate is recommended in future studies of the fission-fusion dynamics. Importantly for conservation and management, our results suggest that the presence of suitable trees providing different microclimates is important for maintaining efficient fission-fusion dynamics.

Acknowledgments We are grateful to those who helped with the fieldwork, particularly C. Duriez, M. Pohlers, P. Zahorowicz, A. Baranowski, A. Arasim, J. Mieczkowska, S. Barthwood, J. van Beek, M. Blaice, M. Cox, A. Domen, A. Domżalska, A. Dorenda, K. Gmitruk, J. Górniak, T. van Grup, K. Gryka, D. Koncewicz, K. Mazurska, A. Misiak, I. Ruczyńska, K. Sachanowicz, H. Zalewska, R. Szordykowski, A. Wower, K. Zając, R. Zwolak, T. Zychowicz, and the members of the Students' Science Club, Academy of Podlasie in Siedlce. We thank two anonymous reviewers for their helpful comments, and E. Stockwell, H. Kingsley, S.A. Zollinger and I. Jarosz for language corrections of the many versions of this manuscript.

Funding information IR was supported by a grant from the National Science Centre, Poland, on the basis of decision number DEC-2013/10/ E/NZ8/00725. KB was financed by the National Science Centre, Poland, grant no. 2015/16/S/NZ8/00158.

Data availability The datasets used in the current study are available from the corresponding author on reasonable request. 


\section{Compliance with ethical standards}

Conflict of interest The authors declare that they have no conflict of interest.

Ethical approval We obtained permission for the field research from the Ministry of Environment of Poland and Local Ethical Commission in Białystok nr 2001/52. All applicable international, national, and/or institutional guidelines for the care and use of animals were followed.

Open Access This article is licensed under a Creative Commons Attribution 4.0 International License, which permits use, sharing, adaptation, distribution and reproduction in any medium or format, as long as you give appropriate credit to the original author(s) and the source, provide a link to the Creative Commons licence, and indicate if changes were made. The images or other third party material in this article are included in the article's Creative Commons licence, unless indicated otherwise in a credit line to the material. If material is not included in the article's Creative Commons licence and your intended use is not permitted by statutory regulation or exceeds the permitted use, you will need to obtain permission directly from the copyright holder. To view a copy of this licence, visit http://creativecommons.org/licenses/by/4.0/.

\section{References}

Aureli F, Schaffner CM, Boesch C, Bearder SK, Call J, Chapman CA, Connor R, Fiore AD, Dunbar RIM, Henzi SP, Holekamp K, Korstjens AH, Layton R, Lee P, Lehmann J, Manson JH, RamosFernandez G, Strier KB, Schaik CP (2008) Fission-fusion dynamics: new research frameworks. Curr Anthropol 49:627-654. https://doi. org/10.1086/586708

Barclay RMR (1994) Constraints in reproduction by flying vertebrates: energy and calcium. Am Nat 144:1021-1031

Bartonička T, Řehák Z (2007) Influence of the microclimate of bat boxes on their occupation by the soprano pipistrelle Pipistrellus pygmaeus: possible cause of roost switching. Acta Chiropterol 9:517-526. https://doi.org/10.3161/1733-5329(2007)9[517:IOTMOB]2.0.CO; 2

Boyles JG (2007) Describing roosts used by forest bats: the importance of microclimate. Acta Chiropterol 9:297-303. https://doi.org/10.3161/ 1733-5329(2007)9[297:DRUBFB]2.0.CO;2

Chaverri G, Gillam EH, Kunz TH (2013) A call-and-response system facilitates group cohesion among disc-winged bats. Behav Ecol 24:481-487. https://doi.org/10.1093/beheco/ars 188

Czenze ZJ, Brigham RM, Hickey AJR, Parsons S (2017) Cold and alone? Roost choice and season affect torpor patterns in lesser short-tailed bats. Oecologia 183:1-8. https://doi.org/10.1007/s00442-016-37071

Dechmann DKN, Kranstauber B, Gibbs D, Wikelski M (2010) Group hunting - a reason for sociality in molossid bats? PLoS One 5: e9012. https://doi.org/10.1371/journal.pone.0009012

Dietz M, Kalko EKV (2006) Seasonal changes in daily torpor patterns of free-ranging female and male Daubenton's bats (Myotis daubentonii). J Comp Physiol B 176:223-231. https://doi.org/10. 1007/s00360-005-0043-x

Dietz C, von Helversen O, Nill D (2009) Bats of Britain, Europe and Northwest Africa. A. \& C. Black, London

Dunbar RIM, Shultz S (2007) Evolution in the social brain. Science 317: 1344-1347. https://doi.org/10.1126/science.1145463

Faliński JB (1986) Vegetation dynamics in temperate lowland primeval forest: ecological studies in Białowieża forest. Dr. W. Junk Publishers, Dordrecht
Fox J (2003) Effect displays in R for generalised linear models. J Stat Softw 8:1-27. https://doi.org/10.18637/jss.v008.i15

Hastie T, Tibshirani R, Friedman J (2009) The elements of statistical learning: data mining, inference, and prediction, 2nd edn. Springer-Verlag, New York

Hoying KM, Kunz TH (1998) Variation in size at birth and post-natal growth in the insectivorous bat Pipistrellus subflavus (Chiroptera: Vespertilionidae). J Zool 245:15-27

Kaňuch P, Krištín A, Krištofík J (2005) Phenology, diet, and ectoparasites of Leisler's bat (Nyctalus leisleri) in the Western Carpathians (Slovakia). Acta Chiropterol 7:249-258. https://doi.org/10.3161/ 1733-5329(2005)7[249:PDAEOL]2.0.CO;2

Kerth G (2008) Causes and consequences of sociality in bats. BioScience 58:737-746. https://doi.org/10.1641/B580810

Kerth G (2010) Group decision-making in fission-fusion societies. Behav Process 84:662-663. https://doi.org/10.1016/j.beproc.2010. 02.023

Kerth G, König B (1999) Fission, fusion and nonrandom associations in female Bechstein's bats (Myotis bechsteinii). Behaviour 136:11871202. https://doi.org/10.1163/156853999501711

Kerth G, Weissmann K, König B (2001) Day roost selection in female Bechstein's bats (Myotis bechsteinii): a field experiment to determine the influence of roost temperature. Oecologia 126:1-9. https://doi.org/10.1007/s004420000489

Kunz TH, Robson SK (1995) Postnatal growth and development in the Mexican free-tailed bat (Tadarida brasiliensis mexicana): birth size, growth rates, and age estimation. J Mammal 76:769-783. https:// doi.org/10.2307/1382746

Kunz TH, Wrazen JA, Burnett CD (1998) Changes in body mass and fat reserves in pre-hibernating little brown bats (Myotis lucifugus). Écoscience 5:8-17. https://doi.org/10.1080/11956860.1998. 11682443

McGuire LP, Jonasson KA, Guglielmo CG (2014) Bats on a budget: torpor-assisted migration saves time and energy. PLoS One 9: e115724. https://doi.org/10.1371/journal.pone.0115724

Nad'o L, Kaňuch P (2015) Swarming behaviour associated with group cohesion in tree-dwelling bats. Behav Process 120:80-86. https:// doi.org/10.1016/j.beproc.2015.09.005

Nad'o L, Chromá R, Kaňuch P (2017) Structural, temporal and genetic properties of social groups in the short-lived migratory bat Nyctalus leisleri. Behaviour 154:785-807. https://doi.org/10.1163/ 1568539X-00003444

Patriquin KJ, Leonard ML, Broders HG, Ford WM, Britzke ER, Silvis A (2016) Weather as a proximate explanation for fission-fusion dynamics in female northern long-eared bats. Anim Behav 122:4757. https://doi.org/10.1016/j.anbehav.2016.09.022

Popa-Lisseanu AG, Bontadina F, Mora O, Ibáñez C (2008) Highly structured fission-fusion societies in an aerial-hawking, carnivorous bat. Anim Behav 75:471-482. https://doi.org/10.1016/j.anbehav.2007. 05.011

Porter WP, Kearney M (2009) Size, shape, and the thermal niche of endotherms. Proc Natl Acad Sci USA 106:19666-19672. https:// doi.org/10.1073/pnas.0907321106

Postawa T, Szubert-Kruszyńska A (2014) Is parasite load dependent on host aggregation size? The case of the greater mouse-eared bat Myotis myotis (Mammalia: Chiroptera) and its parasitic mite Spinturnix myoti (Acari: Gamasida). Parasitol Res 113:1803-1811. https://doi.org/10.1007/s00436-014-3826-8

Pretzlaff I, Kerth G, Dausmann KH (2010) Communally breeding bats use physiological and behavioural adjustments to optimise daily energy expenditure. Naturwissenschaften 97:353-363. https://doi. org/10.1007/s00114-010-0647-1

R Core Team (2019) R: a language and environment for statistical computing. R Foundation for Statistical Computing, Vienna, Austria https://www.R-project.org/ 
Racey PA (1973) Environmental factors affecting the length of gestation in heterothermic bats. J Rep Fer S 19:175-189

Racey PA, Swift SM (1981) Variations in gestation length in a colony of pipistrelle bats (Pipistrellus pipistrellus) from year to year. Reproduction 61:123-129. https://doi.org/10.1530/jrf.0.0610123

Rambaldini DA, Brigham RM (2008) Torpor use by free-ranging pallid bats (Antrozous pallidus) at the northern extent of their range. $\mathrm{J}$ Mammal 89:933-941. https://doi.org/10.1644/08-MAMM-A-029.1

Reckardt K, Kerth G (2007) Roost selection and roost switching of female Bechstein's bats (Myotis bechsteinii) as a strategy of parasite avoidance. Oecologia 154:581-588. https://doi.org/10.1007/ s00442-007-0843-7

Ripperger S, Gunther L, Wieser H, Duda N, Hierold M, Cassens B, Kapitza R, Koelpin A, Mayer F (2019) Proximity sensors on common noctule bats reveal evidence that mothers guide juveniles to roosts but not food. Biol Lett 15:20180884. https://doi.org/10.1098/ rsbl.2018.0884

Ruczyński I (2006) Influence of temperature on maternity roost selection by noctule bats (Nyctalus noctula) and Leisler's bats (N. leisleri) in Białowieża Primeval Forest, Poland. Can J Zool 84:900-907. https://doi.org/10.1139/z06-060

Ruczyński I, Bartoń KA (2012) Modelling sensory limitation: the role of tree selection, memory and information transfer in bats' roost searching strategies. PLoS One 7:e44897. https://doi.org/10.1371/ journal.pone.0044897

Ruczyński I, Bogdanowicz W (2005) Roost cavity selection by Nyctalus noctula and $N$. leisleri (Vespertilionidae, Chiroptera) in Białowieża Primeval Forest, eastern Poland. J Mammal 86:921-930. https://doi. org/10.1644/1545-1542(2005)86[921:RCSBNN]2.0.CO;2

Ruczyński I, Bogdanowicz W (2008) Summer roost selection by treedwelling bats Nyctalus noctula and N. leisleri: a multiscale analysis. J Mammal 89:942-951. https://doi.org/10.1644/07-MAMM-A-134. 1

Ruczyński I, Ruczyńska I (2000) Roosting sites of Leisler's bat Nyctalus leisleri in Białowieża Forest - preliminary results. Myotis 37:55-60

Ruczyński I, Kalko EKV, Siemers BM (2007) The sensory basis of roost finding in a forest bat, Nyctalus noctula. J Exp Biol 210:3607-3615. https://doi.org/10.1242/jeb.009837

Ruczyński I, Zahorowicz P, Borowik T, Hałat Z (2017) Activity patterns of two syntopic and closely related aerial-hawking bat species during breeding season in Białowieża Primaeval Forest. Mammal Res 62:65-73. https://doi.org/10.1007/s13364-016-0298-5

Russo D, Cistrone L, Budinski I, Console G, Corte MD, Milighetti C, Salvo ID, Nardone V, Brigham RM, Ancillotto L (2017) Sociality influences thermoregulation and roost switching in a forest bat using ephemeral roosts. Ecol Evol 7:5310-5321. https://doi.org/10.1002/ ece3.3111

Scantlebury M, Bennett NC, Speakman JR, Pillay N, Schradin C (2006) Huddling in groups leads to daily energy savings in free-living African four-striped grass mice, Rhabdomys pumilio. Funct Ecol 20:166-173. https://doi.org/10.1111/j.1365-2435.2006.01074.x

Silk JB (2007) The adaptive value of sociality in mammalian groups. Philos Trans R Soc B 362:539-559. https://doi.org/10.1098/rstb. 2006.1994

Speakman JR (2008) The physiological costs of reproduction in small mammals. Philos Trans R Soc B 363:375-398. https://doi.org/10. 1098/rstb.2007.2145

Sueur C, King AJ, Conradt L, Kerth G, Lusseau D, Mettke-Hofmann C, Schaffner CM, Williams L, Zinner D, Aureli F (2011) Collective decision-making and fission-fusion dynamics: a conceptual framework. Oikos 120:1608-1617. https://doi.org/10.1111/j.1600-0706. 2011.19685.x

Webber QMR, Willis CKR (2018) An experimental test of effects of ambient temperature and roost quality on aggregation by little brown bats (Myotis lucifugus). J Therm Biol 74:174-180. https://doi.org/ 10.1016/j.jtherbio.2018.03.023

Willis CKR, Brigham RM (2007) Social thermoregulation exerts more influence than microclimate on forest roost preferences by a cavitydwelling bat. Behav Ecol Sociobiol 62:97-108. https://doi.org/10. 1007/s00265-007-0442-y

Willis CKR, Brigham RM, Geiser F (2006) Deep, prolonged torpor by pregnant, free-ranging bats. Naturwissenschaften 93:88-83. https:// doi.org/10.1007/s00114-005-0063-0

Wood SN (2017) Generalized additive models: an introduction with R, 2nd edn. Chapman and Hall/CRC, Boca Raton

Publisher's note Springer Nature remains neutral with regard to jurisdictional claims in published maps and institutional affiliations. 